\title{
Quality of Working Life in the Aspect of Human Resources Management
}

\author{
Irina Lyskova \\ The Economics and Management Department \\ The Komi Republic Academy of State Service and Administration \\ Syktyvkar, Russia \\ E-mail: IrinaLyskova@mail.ru
}

\begin{abstract}
The paper actualizes the main tasks of quality management, substantiates the importance of improving approaches to human resources management of an organization, the formation of effective models of quality management of working life, the quality of human resources in the modern knowledge economy.
\end{abstract}

Keywords-organization; knowledge economy; quality management; quality of working life; human resources management; human resources quality; labor culture; values; labor motivation; labor philosophy

\section{INTRODUCTION}

In the conditions of modern Russian economic system transformation, significant changes in the structure of social and labor relations are currently taking place. A great range of tasks in a modern organization are gaining paramount importance, they include: increasing business processes efficiency, rational organizational resources management, introduction of qualitatively new approaches to human resources management, ensuring labor rights, favorable working conditions, social guarantees, high income, and formation of a working life quality system [1], [2], [3].

However, the problems of dissatisfaction with the conditions and content of labor, the way it is organized, as well as a low level of income inevitably lead to deformation of a person's value priorities. This can be well manifested in a deep work motivation crisis, decline in the need to work, various anti-social characteristics of behavior, expressed in both open and hidden forms, such as work imitation, absenteeism, resistance to inevitable organizational changes, unwillingness to develop professionally, burnout, etc. [4], [5].

\section{THE CONCEPTION OF QUALITY OF WORKING LIFE}

The stabilization of positive dynamics of the economy is largely connected with the system of working life quality. It is essential to note that the ideas on formation of the system of working life quality generally accepted and characteristic of the countries of Western Europe and North America, are still difficult to be applied in Russia. This primarily concerns salary conditions, the level of income of the population, the system of social guarantees, social insurance, etc. For a long time in Russia, in terms of assessing the quality of working life, emphasis was put on the quality of work, that is, the results of work, and not on the conditions of work organization or job satisfaction. In addition, the issue is that there are still practically no standard indicators for assessing the quality of working life in relation to the sphere of production, the specifics of the content of labor, individual and collective characteristics of the quality of working life, etc. Undoubtedly, one cannot ignore the wide range of political, socio-economic and socio-cultural factors affecting the quality of working life. For example, the difficulties of transition to the conditions of the modern market in Russia, the difficulties of forming a new structure of Russian economy, national and cultural characteristics of organization of work, problems of entrepreneurial initiatives development and practice of introducing innovations.

In modern conditions, a powerful theoretical and practical substantiation of the concept of working life quality is required. One of the most critical criteria for the economic and social development of a country is the quality of human resources, their labor potential, the conditions for the formation, development and effective use to the benefit of an individual and organization [6], [7].

Consequently, one of the crucial tasks of a modern manager is to create the most favorable working conditions, which would give each employee the opportunity to apply and demonstrate their knowledge and skills, to contribute to making decisions on professional issues. Thus, it is necessary to create the system of human resources management to provide a high level of employee job satisfaction and their engagement in work processes.

It is indicated that in the process of genesis and development of the "quality of working life" concept, four periods can be distinguished correlating with the main stages of management formation and development: pre-classical, classical, humanistic and strategic. The pre-classical period (until the last quarter of the XIX century) is associated with pre-industrial production. At that time, for obvious reasons, little attention was paid to the quality of working life. Outstanding representatives of classical management theories $(1880$ - 1930) F. Taylor, H. Fayol, H Emerson, L. Urwick, H. Ford, A.K. Gastev, P.M. Kerzhentsev touched upon the issue of the quality of working life, but only to a limited extent. 
Next, at the beginning of the XX century, there were significant changes in the process of labor management. The development of capitalism led to further labor specification, prevalence of collective labor in large-scale factory production and increase in intensity and exploitation in order to bring the maximum profit and benefits to the owners. For that reason labor activities were strictly regulated, and the ideas on workers needs were limited to rationalism and remuneration for work. In the classical period, a technocratic approach to the problems of the quality of working life prevailed, in which the system of staff relationships, individual and collective values and workers' needs were not taken into account. Moreover, there were no tasks on education, development and democratization of social and labor relations, which led to escalation of conflicts in the workplace and in the society overall.

In the second decade of the XX century, the prototypes of modern personnel departments appeared in the countries of Western Europe and the United States, forced to deal with social issues. It is worth mentioning that in 1919 the International Labor Organization was established, the main function of which included regulating labor relations and protection of labor rights of a person.

In the 1930s, E. Mayo, C. Argyris, R. Likert, R. Blake, and others suggested a number of theories of human relations, which soon in the 1950s and 1960s were followed by the theories of human resources by A. Maslow, C. Alderfer, F. Herzberg, D. MacGregor, and others. The humanistic period of the development of the system of working life quality was based on the recognition of numerous human needs, including a desire to grow professionally; more and more attention was paid to social and psychological aspects of labor. In the new theories of labor motivation, it was stated that people's behavior is not strictly rational and that a wide range of factors determine the degree of staff satisfaction with work. By the 1960s, the concepts of fumanization of labor" and industrial democracy" appeared. However, authoritative methods of management prevailed in production for a long time, and material remuneration for labor had the significant role in incentive systems [8].

In the last quarter of the XX century, profound, qualitative changes took place in the organization of the human resources management system. Legal aspects of management, development of material and non-material remuneration system and issues of production activities efficiency gained great attention. Along with operational planning, the tasks of long-term planning of labor resources and their involvement in solving strategic tasks of an organization were raised.

The modern concept of the quality of working life should be linked with the concept of managing intangible assets of an organization and its intellectual resources, which are often considered equal to intellectual capital. The components of intellectual capital were singled out by Thomas Stewart and they include human capital, organizational capital, and consumer capital.

Human capital is known as a set of knowledge, practical skills, creative and intellectual abilities, moral and ethical values, philosophy and work culture, these are, professional and general cultural competences that ensure satisfaction of a wide range of human needs in the field of professional activity.

Organizational capital should also be viewed through the prism of organizational knowledge that combines business processes, technologies, quality systems, management systems, technical and informational support, patents, brands, customer relationships and the overall culture of an organization.

In modern conditions of the market development in terms of quality policy and management quality, consumer capital is getting increased attention. Consumer capital can be characterized as a set of beliefs about customers, consumers, their degree of satisfaction and loyalty. So-called client indicators are being actively taken into account as key performance indicators. In particular, the ideology of customer loyalty is based on the assumption that all customers can be divided into loyal, passive and disloyal. The research of the client base of an organization will ensure its effectiveness. In addition to customer loyalty indicator, customer involvement indicator, customer retention rate, customer satisfaction index, customer profitability rating, customer lifetime value indicator, customer turnover rate, etc. can be monitored [9].

Consumer orientation requires constant organizational development and improvement of human capital. In recent decades, human capital formation is associated with the need to develop intellectual and creative abilities of employees, the development of problem-oriented thinking, leadership, entrepreneurial and managerial skills [10], [11].

Moreover, qualitative characteristics of infrastructure capital, as one of the most significant conditions for ensuring the process and result of the quality of work and working life, are acquiring an exceptionally significant role. The infrastructure capital of an organization includes the technical and technological production equipment, methods for improving modern business processes, the financial system of an organization, the structure of corporate culture, including communication system. The infrastructure capital of an organization is inextricably linked with both customer performance indicators and indicators related to staff. The quality of infrastructure capital provides an increase in the staff satisfaction index, the employee loyalty index, the return on investment indicator aimed at staff training, reduces the staff turnover rate, etc. Accordingly, infrastructure capital directly reflects the target characteristics of working life quality of employees, that is, growth of labor productivity, improvement of working conditions, growth of job satisfaction, and increase in potential of individual and organizational development, satisfaction of a wide range of needs of employees in the field of professional activity.

It is quite natural that value priorities of employees of an organization are inevitably linked with the ability to meet a wide range of needs, specifically in the sphere of professional activity. In modern conditions, there is an increase in the priorities of a socio-psychological nature, 
both at an individual and collective level. Among the most essential needs of such a type one should note the increasing importance of the needs for recognition and prestige, cooperation and communication, self-affirmation, high achievements, independence, novelty and creativity, reliability and stability, joy and pleasure, etc.

\section{THE FACTORS OF FORMING THE SYSTEM OF QUALITY OF WORKING LIFE IN AN ORGANIZATION}

There is a set of factors that influence formation of the quality of working life system in an organization. Traditionally, a wide range of environmental factors of an organization is singled out. To characterize the environmental factors of an organization, the most common are PEST (or STEP) analysis, PESTEL (PESTELE) analysis, Porter's five forces model, and others. These methods together make it possible to track a combination of political, economic, social, technological, legal, environmental and other components that provide an assessment of the competitiveness of an organization, its ability to adapt to changes of the external environment, etc. [12].

We also should highlight the factors of internal environment of an organization. M. Meskon, M. Albert, F Khedouri identified its key elements, which form the essence and content of business processes; they are goals, tasks, structure and people [13]. The quality of working life is largely formed by a combination of socio-economic, organizational and technical factors. Among the most significant characteristics of social and economic factors are parameters reflecting the demographic structure of the staff, the level and quality of medical care for employees of an organization, regulatory documents on ensuring the quality of working life and the system of employees' professional development, etc. The above mentioned characteristics directly affect such areas of formation of working life quality system as payment and incentives, social infrastructure of an organization, increasing the employees' level of income, promotion and protection of labor rights and social security, labor activity motivation, continuous personal development, improving personal skills and others.

Organizational and technical factors include the system production organization, material, technical and technological foundations of business processes in an organization. These conditions determine the quality of working environment, the quality of human resources management, the level of technical and technological production development, effectiveness of labor activity in an organization, the system of labor protection and safety, etc.

Modern business processes quality management system of an organization is constantly evolving, and it is exposed to both external and internal environment effects. The main cause for changes in the internal environment of an organization is often a high level of uncertainty and risk. One of the current trends in quality management system development is risk management. The human factor" plays an exceptionally significant role, when it comes to forming an effective management model in an organization, quality of business processes, and quality of work. Human characteristics (human aspects) are defined as abilities, limitations, and other properties and features related to the design, operation, maintenance of the production system [14].

Special attention is paid to the reliability of the human factor. Human actions have an impact on the reliability of production systems as a whole, the quality of products, ensuring safety, increasing reliability of technical systems, and effectiveness of production costs. However, people's influence can differ; it can be negative, because of errors and violations, or positive, due to high motivation for work, effective monitoring of safety and efficiency of technical and other systems.

Analysis of the human factor impact on reliability is associated with the quality of social and physical environment of an organization. The most prominent characteristic feature of social environment to influence reliability of the human factor is organizational structure. It is defined by the specifics of production tasks distribution, the degree of competence in decisions made, the quality of communication processes, and the quality of management in general. Such processes as effective leadership, partnership, a high level of security significantly affect the employee motivation system and form constructive models of professional behavior.

It is impossible to ignore the factors of physical environment (light, noise, vibration, dirt, humidity, air temperature, etc.) that affect the labor activities and their efficiency. The tension a person feels when performing professional tasks should not exceed certain limits. The level of tension implies a number of physical, cognitive and mental parameters, depending on labor activity type and its specifics. It should be noted that cognitive limitations of human susceptibility include the time to perceive certain external signals and respond to them, it concerns working with equipment and machinery. In addition, cognitive limitations are related to memory properties, so working with a large amount of information requires developing algorithms, mental models or images.

Another thing worth discussing is specifics of human behavior associated with psychic limitations. These limitations are often caused by exhaustion and fatigue or monotonous work, emotional overexcitement, which negatively affect dealing with professional tasks, and decision making, especially.

Accordingly, the reliability of the human factor is associated with external and internal factors. External factors determining the quality of business processes are organizational structure, including hierarchy, remuneration system, employees' qualifications; dynamics of an organization, including duration of work, resources, etc.; the level of technical and technological equipment of labor, conditions, hygiene, safety, labor protection, etc. The internal factors presuppose people's physical facilities and mental abilities (equipment, working conditions, experience, skills, etc.). Among the principal internal factors determining the quality of work there is a person's readiness to perform work, which means their aptitude for employment, health, working conditions, emotional stability and psychological motivation 
(human needs, interests, attitudes, beliefs, career opportunities, professional development, quality of working conditions, etc.).

Along with the reliability of the human factor in the process of improving the quality of working life, it is worth paying attention to prevention of psychosocial risks in the professional sphere, as they may result in unwanted human, social and financial costs. The negative impact of such a risk at the individual level is associated with declining health and well-being and problems in communication at work and in personal life [15].

Psychosocial risks management and stress management in the workplace require targeted action from the management of an organization. Adopting practice in psychosocial risk management provides favorable atmosphere of openness, trust, training and development, involvement in work processes, social responsibility, and high quality of working life and quality of life in general.

The system of psychosocial and risk management includes developing and making strategic steps to improve internal climate and eliminate or minimize the consequences of an unfavorable socio-psychological environment for all stakeholders, ensuring effective safety and health protection systems within an organization. Psychosocial factors are a system of interactions determined by the content of labor activity and working conditions, competencies, needs of employees, etc. Psychosocial risks are defined as potential dangerous effects of psychosocial factors on employees' physical and mental health, and a combination of various disease states: emotional, cognitive, behavioral, psychological reactions harmful aspects of working conditions, disagreements about the content and scope of work, poor system of professional communications leads, which all lead to increased stress and lower quality of work.

The main reasons for the deterioration of the sociopsychological climate in an organization may be related to the specifics of performing official duties, lack of meaning in the content of work, excessive or insufficient workload and pace of work, lack of time or its restrictions, poor organization of work (for example, unpredictable work schedule, working in the evenings or at the weekends), poor organization culture, poor communication system, employees isolation, strained relations with management, low salary, lack of outer motivation, bullying, career stagnation or uncertainty of professional development opportunities, instability, lack of job security, work-life balance and much more.

Psychosocial risks management is inextricably linked with the process of defining team and individual goals and values, development of organizational culture system, business relations ethics, modern philosophy and culture of work. [16], [17], [18], [19], [20], [21], [22], [23], [24].

\section{CONCLUSION}

Thus, the quality of working life is a complex and multifaceted characteristic. Modern quality management requires a thorough analysis of the structure and content of working life quality. Identifying the concept of the quality of working life and its practical implementation for Russia is gaining particular significance. Taking into consideration the positive foreign and national experience in the formation of the system of labor rights and social guarantees of workers, it is essential to provide a differentiated approach to improving the quality of working life based on the individual needs, motivation, goals, and performance indicators of an employee's work. In modern socio-economic conditions, it is necessary to improve the system of labor motivation and stimulation. A modern model of organizational culture and effective leadership can become a powerful tool for developing the system of working life quality. Development of the quality of working life system should be carried out based on a rational state policy ensuring the implementation of strategic plans for Russian economic development, social well-being growth, and quality of life improvement. Deep, qualitative changes in this area should initially take place at the local level by means of developing high culture of professional and managerial labor activity.

\section{REFERENCES}

[1] Adizes, I. S. Mastering Change. The Power of Mutual Trust and Respect in Personal Life, Family Life, Business and Society. Moscow. Mann, Ivanov and Ferber. 2016. - 368 p.

[2] Assen, M. Van, Berg G. Van den, Pietersma, P., (2013). Key management models. The $60+$ models every manager needs to know FT. Prentice Hall. 2-nd edition. 3d ed. Moscow: BINOM. Laboratoriya znaniy. $-319 \mathrm{p}$

[3] Evans, V. (2015). Key strategy tools. The 80+ tools for every manager to build a winning strategy. PEARSON. Moscow: BINOM. Laboratoriya znaniy. $-456 \mathrm{p}$.

[4] Lyskova,I.E. The Main Paradigms of Human Resources Quality Management in the Aspect of Modern Cognitive Economy. The Herald of the Management Faculty of the Saint-Petersburg State University of Economics. 2017, vol. 1. P.1, pp 60-65.

[5] Lyskova, I.E. The problems of human capital management in the aspect of modern knowledge economy. Journal of economy and entrepreneurship. 2017. No. 9 (P. 4) (84-4), pp. 641-645.

[6] Lyskova, I.E. Intellectual Technologies as the Basis of the Innovative Model of Management of Quality of Human Resources of the organization. National Concepts of Quality: the Integration of Education, Science and Business. The Collection of Articles of the VIII International Research and Practice Conference.Saint Petersburg, 2017, pp. 99-102.

[7] Lyskova, I.E. Cognitive and Creative Management as a Basis of Innovative Development of Modern Organization. Public and Private Finances in the Innovative Economy. The Collection of Articles of the International Research and Practice Internet Conference.Plechanov Russian University of Economics. Moscow. 2017, pp. 123-132.

[8] Armstrong, M. Practice of human resource management. 10th ed. $\mathrm{SPb}$.: Peter. 2009. 848 p.

[9] Cokins, G. Perfomance management. Finding the missing pieces (to close the intelligence gap) Moscow: Al'pinaPablisher. 2016. 316 p.

[10] Maxwell, J.C. (2013) The 5 levels of leadership (Proven steps to maximize your potential). Minsk: Popurri. 320 p.

[11] Sherwood, D. Seeing the forest for the trees. A Manager's Guide to Applying Systems Thinking. Moscow: Al'pinaPablisher. 2016, 300 p.

[12] Marr, B.(2014). Key performance indicators. The 75 measures every manager needs to know. PEARSON. Moscow: BINOM. Laboratoriyaznaniy. 340 p. 
[13] Meskon, M., Alber,M., Hedouri, F. The Basics of management. M.: Delo, 2004. $800 \mathrm{p}$.

[14] National standard of the Russian Federation. Risk management. Analysis of the impact on the reliability of the human factor. GOST R IEC 62508-2014. URL: // http://www.consultant.ru

[15] National standard of the Russian Federation. Risk management. Guidelines for the management of psychosocial risk in the workplace. GOST R 55914-2013. URL: // http://www.consultant.ru

[16] Csikszentmihalyi,M. Flow. The psychology of optimal experience. Moscow: Smysl, Al'pina non-fikshn. 2015, 461 p.

[17] Csikszentmihalyi,M. The Evolving Self. A Psychology for the Third Millennium. Moscow:Al'pina non-fikshn. 2013, 420 p.

[18] Schein, E.H. (2002). Organizational culture and leadership. SantPetersburg: PITER. $336 \mathrm{p}$.

[19] Lyskova, I. Moral concepts of modern business processes // International Conference on Judicial, Administrative and Humanitarian Problems of State Structures and Economical Subjects (JAHP 2016) // Atlantis Press, Amsterdam-Hong Kong-Paris. 2016. Pp. 37-41.URL: // www.atlantispress.com/php/pub.php?publication=jahp-16.

[20] Lyskova, I. Socio-Cultural Aspect of Thriftiness. 2nd International Conference on Economy, Management, Law and Education (EMLE 2016) // Advances in Economics. Business and Management Research. Vol. 20. Atlantis Press, Amsterdam-Hong Kong-Paris. 2016. Pp. 152-154.URL: // www.atlantispress.com/php/pub.php?publication=emle-16

[21] Lyskova, I. Main Paradigms of Creative Management in the Aspect of Modern Cognitive Economy // International Conference on Culture, Education and Financial Development of Modern Society (ICCESE 2017) Vol. 103. Atlantis Press, Amsterdam-Hong Kong-Paris. 2017. Pp. 644-649. URL: // Www.atlantispress.com/php/pub.php?publication=iccse-2017

[22] Lyskova, I. Mental Reengineering as an Intellectual Technology of a Human Resources Quality Management in a Modern Organization // Advances in Social Science, Education and Humanities Research. Vol. 205 / The 2nd International Conference on Culture, Education and Economic Development of Modern Society (ICCESE 2018) Atlantis Press, 2018, pp. 903-906. URL: // www.atlantispress.com/php/pub.php?publication=iccse-2018

[23] Lyskova, I. The art of creative thinking as a basis of modern labor philosophy// 3rd International Conference on Judicial, Administrative and Humanitarian Problems of State Structures and Economical Subjects (JAHP 2018) // Atlantis Press, Paris. 2018. Pp. 266-270. URL: // www.atlantis-press.com/proceedings/jahp-18

[24] Lyskova, I.E. The role of the corporative culture in the adaptation of the society to the new challenges of the global economy // Global economy in the XXI century: dialectics of confrontation and solidarity. London, LSP. 2018. Pp. 420-431. 